\title{
EFFECTS OF AGE, GENDER AND EDUCATION LEVEL ON COGNITION IN ELDERLY PEOPLE
}

\author{
Shuba $N^{1}$, Prakash $B^{2}$
}

${ }^{1}$ Associate Professor, Department of Physiology, PSG IMS\&R, Coimbatore.

${ }^{2}$ Former Professor, Department of Neurology, PSG Hospitals, Coimbatore Consultant Neurologist, KMCH, Coimbatore.

\section{ABSTRACT}

\section{BACKGROUND}

With rapidly increasing number of older people in our community cognitive impairment is a growing public health concern in India. It affects the quality of life for the person affected and the caregiver. By preserving the function, we can help older adults to remain independent for as long as possible.

The aim of this study is to investigate the cognitive function in elderly people in various age groups and to find correlation of gender and education with cognition.

\section{MATERIALS AND METHODS}

This is a cross-sectional study conducted on 100 elderly people above 60 years at PSG Hospitals, Coimbatore. Cognition was assessed by Mini-Mental State Examination (MMSE) and Modified Mini-Mental Status examination (3MS) and was scored for 30 and 100 respectively. Correlation of age, gender and education with cognition scores was found. Statistical analysis was done using SPSS software by independent $t$ test and chi square test and $p$ value $<0.05$ was considered to be statistically significant.

\section{RESULTS}

We found statistically significant decline in cognition scores in elderly people as age advances by both tests (p $<0.001)$. Correlation of gender with cognition scores was not found to be significant ( $p=0.254$ and 0.268 ) and correlation of education with cognition scores showed decreased cognition in persons with lower level of education.

\section{CONCLUSION}

In general, we detected a significant decline in cognitive scores as age advances by both MMSE and 3MS. Higher education and younger age group were associated with better cognitive performance. By identifying those people at risk and by evaluation of any causes for cognitive decline and by proper treatment at an early stage, dementia can be prevented.

\section{KEYWORDS}

Cognition, Dementia, Education, Gender, MMSE, 3MS.

HOW TO CITE THIS ARTICLE: Shuba N, Prakash B. Effects of age, gender and education level on cognition in elderly people. J. Evolution Med. Dent. Sci. 2017;6(95):6952-6956, DOI: 10.14260/jemds/2017/1509

\section{BACKGROUND}

The elderly population in India above 60 years was $8 \%$ in 2010, is expected to increase to $19 \%$ in 2050 according to United Nations Population Division (UN 2011). By 2050, India's 60 and older population is expected to encompass 323 million people.(1) Ageing entails many physical, biological, chemical, and psychological changes. Ageing can have diverse effects on cognitive function. Cognitive impairment affects the quality of life for the person affected and the caregiver.

In 2010, 3.7 million Indians over 60 years had dementia and are expected to double by 2030 . Prevalence rates of mild cognitive impairment varies from $3 \%$ to as high as $59 \%$ with a conversion rate to dementia varying from $8 \%$ to $15 \%$ shows the need for diagnostic tests for dementia.(2)

Mini-Mental state Examination (MMSE), by Folstein et al in 1975 is the most widely used standardised instrument for cognitive impairment in the world.(3) Modified Mini-Mental status Examination (3MS) was developed by Teng and Chui in 1987 , it is an expanded version of MMSE.

'Financial or Other Competing Interest': None.

Submission 08-11-2017, Peer Review 08-12-2017,

Acceptance 14-12-2017, Published 23-12-2017.

Corresponding Author:

Dr. Shuba N.

2F, May flower Brookefields Apts,

62-A, Krishnasamy Road, R. S. Puram,

Coimbatore-641002, Tamilnadu.

E-mail:shubaphysio@gmail.com

DOI: $10.14260 /$ jemds $/ 2017 / 1509$
The 3MS is significantly a better predictor of functional outcome than the MMSE and is found to have higher sensitivity.(4) Even though various studies show decline in cognition as age advances, there are not much studies involving correlation of various factors with cognition in elderly people. This study finds the correlation of various physiological factors among elderly people with cognitive impairment.

We tested the hypothesis that age, gender and education play an important role in cognitive function in elderly people. By preserving function, we can help older adults remain independent for as long as possible, which can improve their quality of life and delay the need for costly longterm care. By this study elderly people who are at risk of developing dementia and Alzheimer's disease can be identified and by initiating effective treatment and care, the disease can be prevented or progression of the disease can be slowed down.

\section{Objective}

The objective of the study is to assess the cognitive function in elderly people above 60 years by MMSE and 3MS, and to find correlation of gender and education level with cognitive impairment.

\section{MATERIALS AND METHODS}

This is a cross-sectional study done by collecting data afresh from study participants. Clearance from Human Ethics Committee, PSG IMS\&R was obtained and the study was 
conducted on 100 elderly persons above 60 years. The subjects were selected for the study by convenience sampling method from Medicine Outpatient Department and from Master Health Check-up Department which has easy accessibility of old patients. Patients above 60 years who were available at that time and willing to participate in the study were recruited for the research. Informed consent was obtained.

Detailed relevant history regarding complaints, personal history, details of diabetes and hypertension and its treatment was obtained and details regarding investigations done were obtained from the patients.

Both males and females above 60 years of age and with diabetes and hypertension under control were included in the study. Persons with history of stroke, psychiatry problem, hearing impairment, with uncontrolled diabetes and hypertension and with other metabolic abnormalities were excluded from the study.

MMSE and 3MS were conducted on 100 persons and was scored for 30 and 100 respectively.

The MMSE tests global cognitive function, consists of simple tasks, grouped into seven cognitive domains including orientation to time, orientation to place, registration of three words, attention and calculation, recall of three words, language, and visual construction. The test yields a total score of 30 and provides a picture of a subject's present cognitive performance based on direct observation of completion of test tasks. Levels of impairment have also been classified as none (24-30); mild (19-23); moderate (10-18) and severe ( $\leq 9) .(5)$

Teng and Chui (1987) developed an expanded version of the MMSE, the Modified Mini-Mental State Examination (3MS).(6) The 3MS retains the brevity, ease of administration, and objective scoring of the MMSE but broadens the range of scores from $0-30$ to $0-100$. The $3 \mathrm{MS}$ adds four additional questions (date and place of birth, word fluency, similarities, and delayed recall of words), provides additional scoring guidelines, and increases the range of item scores to produce a maximum total score of 100 points. The goal of $3 \mathrm{MS}$ was to enhance sensitivity, reliability, and validity, and sample a broader range of cognitive capacity and difficulty levels. Additionally, a single administration of the 3MS also yields an MMSE score.

Modified Mini-Mental Status Examination (3MS) was done along with MMSE and its score was obtained for 100. Levels of impairment as per 3MS scores are classified as normal cognition (78-100), moderate impairment (48-77) and severe impairment $(\leq 47) .(5,7)$ It took about 20 minutes for these tests.

\section{The 100 elderly people were divided into 5 age groups as follows \\ Group I: 61-65 years; Group II: 66-70 years; Group III: 71-75 years; Group IV: 76-80 years and Group V: > 80 years.}

According to the levels of education, 100 persons were divided into 5 categories as follows

Group A: Not gone to school; Group B: Few years of Primary education; Group C: Completed Primary education; Group D: Completed SSLC; Group E: Completed 12th Standard or equivalent studies.

Statistical analysis was done using SPSS software version 19 , by Chi square test and Independent t test, $p$ value $<0.05$ was taken as significant.

\section{RESULTS}

The Number of Persons in each Age Group was as follows Group I (61-65 years): 24; Group II (66-70 years): 22; Group III (71-75 years): 30 .

Group IV (76-80 years): 18; Group V ( $>80$ years): 6. There were 56 males and 44 females.

\section{The Number of Persons in each Education Category was as follows}

Group A (Not gone to school): 24; Group B (Few years of Primary education): 28.

Group C (Completed Primary education): 38; Group D (Completed SSLC): 6.

Group E (Completed 12th Standard or equivalent studies): 4.

\begin{tabular}{|c|c|c|c|}
\hline Age Group & N & MMSE \pm SD & 3MS \pm SD \\
\hline Group I (61-65 years) & 24 & $24.86 \pm 3.01$ & $79.32 \pm 8.03$ \\
\hline Group II (66-70 years) & 22 & $21.79 \pm 3.63$ & $77.29 \pm 8.28$ \\
\hline Group III (71-75 years) & 30 & $20.44 \pm 3.54$ & $72.48 \pm 9.38$ \\
\hline Group IV (76-80 years) & 18 & $18.80 \pm 3.45$ & $65.35 \pm 9.64$ \\
\hline Group V (> 80 years) & 6 & $15.89 \pm 1.90$ & $60.11 \pm 8.83$ \\
\hline \multicolumn{3}{|c|}{ Table 1. Mean \pm SD of MMSE and 3MS Scores } \\
in Various Age Groups \\
\hline
\end{tabular}

$\mathrm{N}=$ Number of persons.

As from Table 1, we observe progressive decline in cognition scores as age advances both in MMSE and 3MS scores.

Regarding categorisation of cognition scores by MMSE, among 100 elderly people, 38 had normal cognition, 45 had mild cognitive impairment and 17 had moderate cognitive impairment. Regarding categorising of cognition scores among different age groups, considering MMSE, group I had normal cognition, group II and III had mild cognitive impairment and group IV and $V$ had moderate cognitive impairment.

Regarding categorisation of cognition scores by 3MS, among 100 elderly, 40 had normal cognition, 54 had moderate cognitive impairment and 6 had severe cognitive impairment. As per age groups, considering 3MS, group I had normal cognition, group II, III, IV and V had moderate cognitive impairment.

The MMSE and 3MS test scores were compared among 5 age groups by independent $t$ test as between I and II, I and III, I and IV, I and V, II and III, II and IV, II and V, III and IV, III and V, IV and $V$ and if there is any statistically significant difference found between any 2 groups. The $p$ value $<0.05$ was taken to be statistically significant.

\begin{tabular}{|c|c|c|}
\hline Between Groups & p value in MMSE & p value in 3MS \\
\hline $1 \& 2$ & $0.003^{* *}$ & $0.405 \mathrm{NS}$ \\
\hline $1 \& 3$ & $0.000^{* * *}$ & $0.011^{*}$ \\
\hline $1 \& 4$ & $0.000^{* * *}$ & $0.000^{* * *}$ \\
\hline $1 \& 5$ & $0.000^{* * *}$ & $0.000^{* * *}$ \\
\hline $2 \& 3$ & $0.194 \mathrm{NS}$ & $0.064 \mathrm{NS}$ \\
\hline $2 \& 4$ & $0.008^{* *}$ & $0.000^{* * *}$ \\
\hline $2 \& 5$ & $0.000^{* * *}$ & $0.000^{* * *}$ \\
\hline $3 \& 4$ & $0.127 \mathrm{NS}$ & $0.016^{*}$ \\
\hline $3 \& 5$ & $0.000^{* * *}$ & $0.002^{* *}$ \\
\hline $4 \& 5$ & $0.007^{* *}$ & $0.177 \mathrm{NS}$ \\
\hline \multicolumn{2}{|c|}{ Table 2. The p values on Comparison of MMSE and 3MS } \\
Between 2 Age Groups by Independent t test \\
\hline
\end{tabular}

${ }^{*} \mathrm{p}<0.05,{ }^{* *} \mathrm{p}<0.01,{ }^{* * *} \mathrm{p}<0.001$, NS-Not significant 
Table 2 shows that there is statistically significant difference in cognition scores between various age groups as represented by $\mathrm{p}$ values. There is highly statistical significant difference in cognition scores between age groups I and IV, I and V, II and IV, II and V and III and V.

Cognition scores by MMSE and 3MS tests in various age groups were also analysed by chi square test, which was found to be highly statistically significant with $p$ value $<0.001$.

\begin{tabular}{|c|c|c|c|c|c|c|}
\hline \multicolumn{2}{|c|}{ Age Group } & $\begin{array}{c}I \\
(61-65 \\
\text { years }) \\
N=24\end{array}$ & $\begin{array}{c}\text { II } \\
(66-70 \\
\text { years }) \\
\mathrm{N}=22\end{array}$ & $\begin{array}{c}\text { III } \\
(71-75 \\
\text { years) } \\
\mathrm{N}=30\end{array}$ & $\begin{array}{c}\text { IV } \\
(76-80 \\
\text { years) } \\
\mathrm{N}=18\end{array}$ & $\begin{array}{l}V \\
(>80 \\
\text { years }) \\
N=6\end{array}$ \\
\hline \multirow{3}{*}{$\begin{array}{l}\text { MMSE } \\
\text { category }\end{array}$} & 1 & $16(67)$ & $14(64)$ & $8(27)$ & $0(0)$ & $0(0)$ \\
\hline & 2 & $6(25)$ & $8(36)$ & $17(57)$ & $12(67)$ & $2(33)$ \\
\hline & 3 & $2(8)$ & $0(0)$ & $5(16)$ & $6(33)$ & $4(67)$ \\
\hline \multirow{3}{*}{$\begin{array}{c}\text { 3MS } \\
\text { category }\end{array}$} & 1 & $16(67)$ & $14(64)$ & $10(33)$ & $0(0)$ & $0(0)$ \\
\hline & 2 & $8(33)$ & $8(36)$ & $18(60)$ & $16(89)$ & $4(67)$ \\
\hline & 3 & $0(0)$ & $0(0)$ & $2(7)$ & $2(11)$ & $2(33)$ \\
\hline \multicolumn{7}{|c|}{$\begin{array}{c}\text { Table 3. Number and Percentage of Persons on } \\
\text { Categorisation of MMSE and 3MS Scores in Various } \\
\text { Age Groups }\end{array}$} \\
\hline
\end{tabular}

$\mathrm{N}=$ Number of persons in each age group, Data are represented as number (percentage) for each group, MMSE category: 1- Normal cognition, 2- Mild cognitive impairment, 3- Moderate cognitive impairment. 3MS category: 1- Normal cognition, 2- Moderate cognitive impairment, 3- Severe cognitive impairment.

From the Table 3, we observe, as age advances there are more number of persons with mild, moderate and severe cognitive impairment and less number of persons with normal cognition by both MMSE and 3MS tests.

Regarding correlation of gender with cognition scores, there is no statistically significant difference in cognition scores between males and females as represented in Table: 3 with p values 0.254 and 0.268 for MMSE and 3MS respectively. Even though females have slightly less cognition scores when compared to males in both MMSE and 3MS, it was not statistically significant by independent $t$ test. (Table: 4 ).

\begin{tabular}{|c|c|c|c|c|}
\hline Test & Gender & $\mathbf{N}$ & Mean \pm SD & p value \\
\hline \multirow{2}{*}{ MMSE } & Male & 56 & $22.90 \pm 5.01$ & \multirow{2}{*}{0.254 NS } \\
\cline { 2 - 4 } & Female & 44 & $21.52 \pm 4.09$ & \\
\hline \multirow{2}{*}{$3 \mathrm{MS}$} & Male & 56 & $71.4 \pm 14.56$ & \multirow{2}{*}{$0.268 \mathrm{NS}$} \\
\cline { 2 - 4 } & Female & 44 & $68.9 \pm 11.68$ & \\
\hline \multirow{2}{*}{ Table 4. Correlation of Gender with MMSE and 3MS } \\
\hline
\end{tabular}

N- Number of persons; NS- Not statistically significant.

On categorisation of cognition scores as per MMSE in various education levels, we find more persons with severe cognitive impairment in group A (58\%), equal number of persons with moderate cognitive impairment and normal cognition in group B (43\%), more persons with normal cognition in group C (53\%), D (60\%) and E (68\%). (Figure: 1 ).

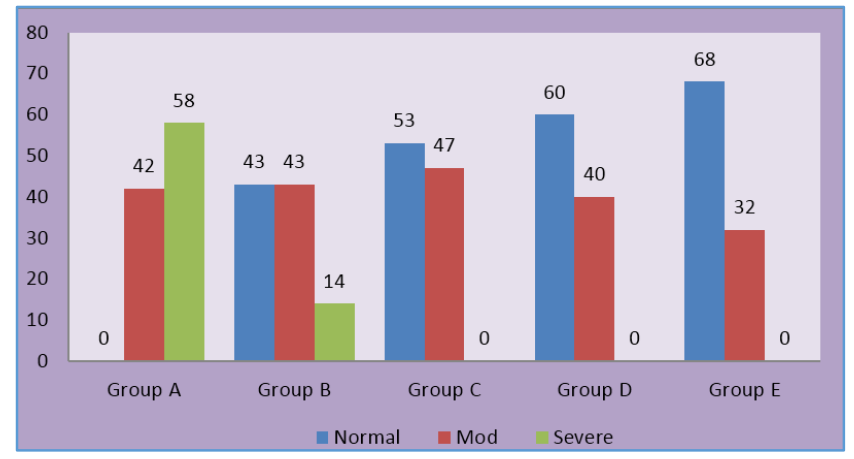

Figure 1. Percentage of Persons on Categorising of MMSE Scores According to Education Level

Group A: Not gone to school, Group B: Few years of Primary education, Group C: Completed Primary education, Group D: Completed SSLC, Group E: Completed 12th Standard or equivalent studies. Normal: Normal cognition, Mod: Moderate cognitive impairment, Severe: Severe cognitive impairment

On categorisation of cognition scores according to $3 \mathrm{MS}$ in various education levels, we find more persons with severe cognitive impairment in group A (34\%), 3\% in group B. More persons with moderate cognition impairment in group $A$ $(58 \%)$ and B (68\%). There are equal number of persons with normal cognition and moderate cognitive impairment in group C $(50 \%)$, more persons with normal cognition in group D $(80 \%)$. All persons in group E (100\%) have normal cognition. (Figure: 2).

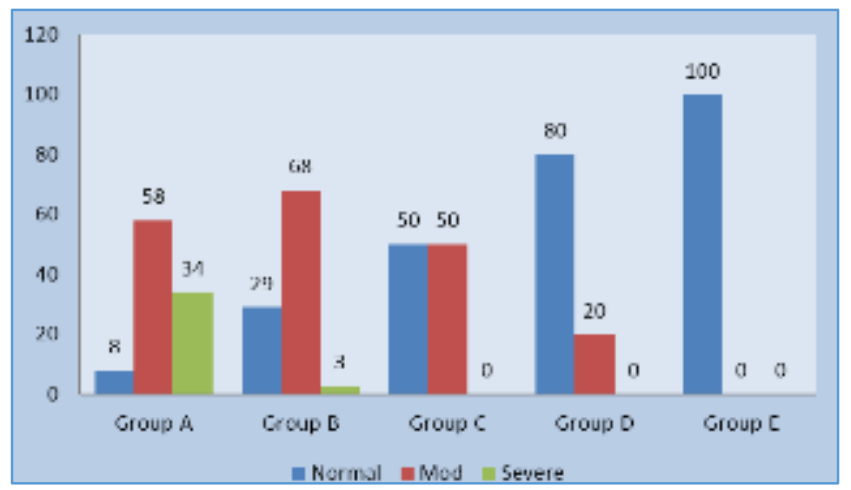

Figure 2. Percentage of Persons on Categorising 3MS Scores According to Education Level

Group A: Not gone to school, Group B: Few years of Primary education, Group C: Completed Primary education, Group D: Completed SSLC, Group E: Completed 12 $12^{\text {th }}$ Standard or equivalent studies. Normal: Normal cognition, Mod: Moderate cognitive impairment, Severe: Severe cognitive impairment.

\section{DISCUSSION}

Poor cognitive function contributes to dementia and other chronic health conditions. Yet cognitive health among older adults in developing countries is understudied, particularly in India.(8) Late-life cognitive impairment ranges from normal age-related change which is mildest, through mild cognitive impairment (MCI), to dementia in most severe forms. Even mild cognitive decline can generate significant levels of functional dependence and reduce quality of life.(9) 
Age remains the strongest risk factor for dementia, especially for Alzheimer disease (AD).(10) AD prevalence doubles every 5 years after the age of 60.(11) So we have taken elderly persons above 60 years for our study. We observed progressive decline in cognitive function as age advances by gradual decrease in MMSE and 3MS tests (Table: 1), most significant decrease noted between group I (61-65 years) and group IV (75-80 years) ; group I and group V ( $>80$ years); group II (66-70 years) and group IV (75-80 years); group II and group V ( $>80$ years). Results from the MRC trial of assessment and management of older people in the community showed high prevalence of cognitive impairment among people aged $>$ 75 years, similar to our study.(12) Population based study of 3050 Mexican Americans aged 65 and above was followed for 11 years and found that age was negatively correlated with global cognitive domains and the total MMSE scores.(13)

It has been proven that gender has an important effect on cognitive impairment in some studies but not in many studies.(14,15) Women have higher risk of developing AD than age matched men and also show significantly age-related faster decline and greater deterioration of cognition than elderly male.(16,17) There is no statistically significant difference in cognition scores between males and females in our study, as represented in Table 4 with p values 0.254 and 0.268 for MMSE and 3MS respectively, even though females have slightly less cognition scores when compared to males in both MMSE and 3MS. According to a study by Matallana D et al, gender was not associated with global cognitive domains or total MMSE scores.(13)

Several population based studies have shown that the prevalence of dementia in women older than 80 is higher than that in men.(15,18,19) It seems cognitive ageing occurs differently in men and women, memory declines more steeply in men than in women while psychomotor speed declines more steeply in women.(16) Studies have reported that men demonstrated larger amygdale and thalamus volumes when compared with females whereas females show large size of hippocampus than males. There are relatively larger number of androgen receptors in amygdala and oestrogen receptor in hippocampus, which explains advantage of males on spatial skills and females on verbal tasks.(16)

Education has been considered as a protective factor for cognitive decline in some studies(20,21) but not in others. $(22,23)$ Subjects with $>12$ years of education performed better than those with $<3$ years of education in total MMSE scores.(13) Similarly, we got more persons with normal cognition in group $\mathrm{C}, \mathrm{D}$ and $\mathrm{E}$ with education above 5 years of schooling and severe cognitive impairment in group A (not gone to school) in both MMSE and 3MS with all persons having normal cognition in group $\mathrm{E}$ in $3 \mathrm{MS}$.

Education is believed to contribute to higher cognitive reserve as persons with higher education qualification are likely to engage in more cognitively stimulating activities and physical activities which limit cognitive decline by building brain networks to compensate for stressors and insults to brain. $(24,25)$

Contrast to our study, Scarmeas $\mathrm{N}$ et al(20) found faster rate of cognitive decline in incident $\mathrm{AD}$ patients with higher education attainment compared to those with lower education. Similar results were obtained in studies by Teri $\mathrm{L}$ et al and Wilson RS et al.(23,26) Higher education is associated with reduced risk of cognitive decline and development of dementia in normal ageing.(27)

Hooren et al found that there is age-related decrease in executive function, verbal fluency, verbal memory and cognitive speed tasks in healthy individuals. They also found that education had a substantial effect on cognitive function and participants with middle or high level of education performed better on cognitive tests than participants with low level of education.(28)

Many prospective studies have suggested that higher education is associated with reduced risk of incident AD, similar to our study. $(20,21,24)$ Education is the single component that explains the most gender discrepancy in late-life cognitive functioning, accounting for about $60 \%$ of the disparity. (29)

The limitation of our study includes small sample size and the results cannot be generalised as it was conducted in a tertiary care centre. We studied the cognitive function using only two tests; other assessment measures would produce some difference. Other contributing factors, both physiological and pathological for cognitive impairment were not considered in the study.

Future research should consider various assessment measures for cognitive impairment and contributing factors. It should focus whether corrections of some predictors of cognitive decline in later life like lifestyle learning, volunteering work, participation in social and leisure activities could delay onset of cognitive impairment.

It has been stated that, identifying the demographic, biological and psychosocial factors that help people maintain or enhance their cognitive health as they grow older becomes a major public health goal for our country. (30) We found the effect of age, gender and education in elderly people in a tertiary care hospital.

\section{CONCLUSION}

In general, we detected a significant decline in cognitive scores as age advances by both MMSE and 3MS. In conclusion, our findings support that there is definite decline in cognition, as age advances in normal healthy old people, but there is no difference in cognitive function in elderly males and females. We find strong evidence for a positive effect of education on cognitive function. Higher education and younger age group were associated with better cognitive performance. By identifying those people at risk and by evaluation of any causes for cognitive decline and by proper treatment at an early stage, dementia can be prevented. Improving cognitive functioning among elders is important for the Ageing societies in India.

\section{REFERENCES}

[1] Population Reference Bureau. Today's research on aging. No. 25. March, 2012;1.

[2] Evans DA. The epidemiology of dementia and Alzheimer's disease: an evolving field. J Am Geriatr Soc 1996;44(12):1482-3.

[3] Folstein MF, Folstein SE, McHugh PR. "Mini-mental state". A practical method for grading the cognitive state of the patients for the clinician. J Psychiatr Res 1975;12(3):189-98.

[4] Bland RC, Newman SC. Mild dementia or cognitive impairment: the modified mini-mental state examination (3MS) as a screen for dementia. Can J Psychiatry 2001;46(6):506-10. 
[5] Mungas D. In-office mental status testing: a practical guide. Geriatrics 1991;46(7):54-8, 63, 66.

[6] Teng EL, Chui HC. The modified mini-mental state (3MS) examination. J Clin Psychiatry 1987;48(8):314-8.

[7] McDowell I, Kristjansson B, Hill GB, et al. Community screening for dementia: the mini mental status examination (MMSE) and modified mini mental status examination (3MS) compared. J Clin Epidemiol 1997;50(4):377-83.

[8] Kalaria RN, Maestre GE, Arizaga R, et al. Alzheimer's disease and vascular dementia in developing countries: prevalence, management, and risk factors. Lancet Neurol 2008;7(9):812-26.

[9] Millan-Calenti JC, Tubio J, Pita-Fernandez S, et al. Cognitive impairment as predictor of functional dependence in an elderly sample. Arch Gerontol Geriatr 2012;54(1):197-201.

[10] Fratiglioni L, Launer LJ, Andersen K, et al. Incidence of dementia and major subtypes in Europe: a collaborative study of population-based cohorts. Neurologic diseases in the elderly research group. Neurology 2000;54(11 Suppl 5):S10-5.

[11] Nussbaum RL, Ellis CE. Alzheimer's disease and Parkinson's disease. N Engl J Med 2003;348(14):135664.

[12] Rait G, Fletcher A, Smeeth L, et al. Prevalence of cognitive impairment: results from the MRC trial of assessment and management of older people in the community. Age Ageing 2005;34(3):242-8.

[13] Matallana D, Santacruz CD, Cano C, et al. The relationship between education level and mini mental state examination domains among older Mexican Americans. J Geriatr Psychiatry Neurol 2011;24(1):918.

[14] Kukull WA, Higdon R, Bowen JD, et al. Dementia and Alzheimer disease incidence: a prospective cohort study. Arch Neurol 2002;59(11):1737-46.

[15] Andersen K, Launer LJ, Dewey ME, et al. Gender differences in the incidence of $\mathrm{AD}$ and vascular dementia: the EURODEM studies. EURODEM incidence research group. Neurology 1999;53(9):1992-7.

[16] Li R, Singh M. Sex difference in cognitive impairment and Alzheimer's disease. Front Neuroendocrinol 2014;35(3):385-403.

[17] Read S, Pedersen NL, Gatz M, et al. Sex differences after all those years? Heritability of cognitive abilities in old age. J Gerontol B Psychol Sci Soc Sci 2006;61(3):P13743.
[18] Heeren TJ, Lagaay AM, Hijmans W, et al. Prevalence of dementia in the oldest old of a Dutch community. J Am Geriatr Soc 1991;39(8):755-9.

[19] Bachman DL, Wolf PA, Linn R, et al. Prevalence of dementia and probable senile dementia of the Alzheimer type in the Framingham study. Neurology 1992;42(1):115-9.

[20] Scarmeas N, Albert SM, Manly JJ, et al. Education and rates of cognitive decline in incident Alzheimer's disease. J Neurol Neurosurg Psychiatry 2006;77(3):308-16.

[21] Manly JJ, Tang MX, Schupf N, et al. Frequency and course of mild cognitive impairment in a multiethnic community. Ann Neurol 2008;63(4):494-506.

[22] Suh GH, Ju YS, Yeon BK, et al. A longitudinal study of Alzheimer's disease: rates of cognitive and functional decline. Int J Geriatr Psychiatry 2004;19(9):817-24.

[23] Wilson RS, Li Y, Aggarwal NT, et al. Education and the course of cognitive decline in Alzheimer's disease. Neurology 2004;63(7):1198-202.

[24] Wilson RS, Bennett DA, Bienias JL, et al. Cognitive activity and cognitive decline in a biracial community population. Neurology 2003;61(6):812-6.

[25] Ghisletta P, Bickel JF, Lövdén M. Does activity engagement protect against cognitive decline in old age? Methodological and analytical considerations. J Gerontol B Psychol Sci Soc Sci 2006;61(5):P253-61.

[26] Teri L, McCurry SM, Edland SD, et al. Cognitive decline in Alzheimer's disease: a longitudinal investigation of risk factors for accelerated decline. J Gerontol A Biol Sci Med Sci 1995;50A(1):M49-55.

[27] Stern Y. Cognitive reserve. Neuropsychologia 2009;47(10):2015-28.

[28] van Hooren SA, Valentijn AM, Bosma H, et al. Cognitive functioning in healthy older adults aged 64-81: a cohort study into the effects of age, sex, and education. Neuropsychol Dev Cogn B Aging Neuropsychol Cogn 2007;14(1):40-54.

[29] Lee J, Shih R, Feeney K, et al. Gender disparity in late-life cognitive functioning in India: findings from the longitudinal aging study in India. J Gerontol B Psychol Sci Soc Sci 2014;69(4):603-11.

[30] Hendrie HC, Albert MS, Butters MA, et al. The NIH cognitive and emotional health project. Report of the critical evaluation study committee. Alzheimer's Dement 2006;2(1):12-32. 